\title{
Tackling Inflammatory Heart Disease: How to Get Dirty Glasses Clean with Dirty Towels
}

\author{
Urs Eriksson \\ Department of Cardiology, University Hospital, and Cardiovascular Research, Center for Integrative Human \\ Physiology, University Zürich-Irchel, Zürich, Switzerland
}

Inflammatory cardiomyopathy denotes a primary, acquired cardiomyopathy, defined by the presence of a chronic inflammatory process $[1,2]$. Currently, inflammatory cardiomyopathy is estimated to account for $10-$ $50 \%$ of cases with dilated cardiomyopathy [1-3]. Recent progresses in basic and clinical research support the concept that acute, mostly virus-mediated myocarditis triggers a complex system of interactions of host and infective agent-related factors, promoting heart failure development. In this context, heart-specific autoimmunity might play a particularly important role [3-5].

The term 'inflammatory cardiomyopathy' simply denotes the immunohistochemical detection of focal or diffuse mononuclear infiltrates with $\geq 14$ leukocytes $/ \mathrm{mm}^{2}$ $\left(\mathrm{CD}^{+} \mathrm{T}\right.$ lymphocytes and/or $\mathrm{CD}^{+} 8^{+}$macrophages) in the myocardium, but largely neglects variations in the histological phenotype $[4,6]$. From this point of view, we still lack experience in linking morphological findings to a presumed specific clinical disease course. As an exception, we have to mention giant cell myocarditis, a distinct disease entity with typical histological appearance and unfavorable prognosis [7].

The availability of novel molecular-biological techniques has allowed the identification of genomes of various infective agents supposed to trigger and promote inflammatory heart disease [4]. Whereas historical studies failed to show an effect of immunosuppressive treatments in patients with active myocarditis $[8,9]$, several, albeit small, studies have suggested a potential effect of immunosuppressive treatments in subgroups of patients with inflammatory cardiomyopathy $[10,11]$. In fact, it appears that patients with histological evidence for ongoing inflammation in the absence of residual viral genome in heart biopsy samples or evidence for heart-specific autoimmunity might benefit from immunosuppression. Antiviral treatment, on the other hand, might be beneficial for patients suffering from acute viral myocarditis [12]. Unfortunately, these studies were rather small and do not yet provide sufficient evidence to draw firm conclusions regarding generally accepted recommendations for the management of all patients with inflammatory heart disease. In order to translate recent progress in basic and preliminary clinical research into clinical practice, we therefore urgently need more data on these patients.

The German Transregional Collaborative Research Centre 'Inflammatory Cardiomyopathy - Molecular Pathogenesis and Therapy' [13], details of which are published in Cardiology, aims to establish a comprehensive research registry on the diagnostics, therapy and disease outcomes of patients with inflammatory cardiomyopathy. Unfortunately, data collection and interpretation are greatly complicated by the low incidence of diagnosed acute myocarditis, the clinical variability, the lack of sensitivity and specificity of routine cardiac tests and the

\section{KARGER \\ Fax +4161306 1234 E-Mail karger@karger.ch} www.karger.com

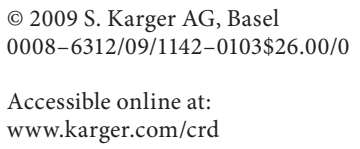

Prof. Dr. Urs Eriksson

Department of Cardiology, University Hospital

Rämistrasse 100

$\mathrm{CH}-8091$ Zürich (Switzerland)

Tel. +41 44255 4939, Fax +41 44255 8701, E-Mail urs.eriksson@usz.ch 
changing patterns of pathogenic cardiotropic microorganisms $[3,4,14,15]$. From this point of view, it is practically impossible to cover all variables which might become important for the understanding and management of inflammatory heart disease. In addition, the successive improvement of diagnostic modalities, i.e. cardiac MRI [16] or molecular biology [4, 14], warrants ongoing and critical re-evaluation of data validity. As such, the currently available methodology will always be unsatisfactory to answer our most recent questions. Thus, we are forced to - as the famous Danish physicist Niels Bohr (1885-1962) put it - get 'dirty glasses clean with dirty towels and dirty dishwater'. Nevertheless, the described registry already covers a fairly large number of included cases and most of the variables currently considered as important in inflammatory cardiomyopathy. Despite important drawbacks, the registry might therefore represent a first step to the acquisition of relevant clinical, microbial and pathological data on inflammatory cardio- myopathy patients, to the analyses of specific sub-groups as well as to potential therapeutic regimens.

I hope that the publication of this methodology paper prompts other centers in Europe to either join an existing registry or to build up their own collaborative databases - ideally by using the same inclusion criteria and standardized protocols. This will be the only way to advance our knowledge on the disease course, diagnostic strategies and appropriate treatments in such a complex disease entity as inflammatory cardiomyopathy. Getting dirty glasses clean with dirty towels, it works somehow - but a philosopher would not believe it.

\section{Acknowledgments}

Urs Eriksson acknowledges support from the Swiss Heart Foundation and the Swiss Life Foundation. He holds a Swiss National Foundation professorship.

\section{References}

1 Felker GM, Hu W, Hare JM, Hruban RH, Baughman KL, Kasper EK: The spectrum of dilated cardiomyopathy: the Johns Hopkins experience with 1,278 patients. Medicine (Baltimore) 1999;78:270-283.

-2 D’Ambrosio A, Patti G, Manzoli A, Sinagra G, Di LA, Silvestri F, et al: The fate of acute myocarditis between spontaneous improvement and evolution to dilated cardiomyopathy: a review. Heart 2001;85:499-504.

-3 Kallwellis-Opara A, Dorner A, Poller WC, Noutsias M, Kuhl U, Schultheiss HP, et al: Autoimmunological features in inflammatory cardiomyopathy. Clin Res Cardiol 2007; 96:469-480.

4 Dennert R, Crijns HJ, Heymans S: Acute viral myocarditis. Eur Heart J 2008;29:20732082.

5 Blyszczuk P, Valaperti A, Eriksson U: Future therapeutic strategies in inflammatory cardiomyopathy: insights from the experimental autoimmune myocarditis model. Cardiovasc Hematol Disord Drug Targets 2008;8: 297-305.

6 Baughmann KL: Diagnosis of myocarditis: death of Dallas criteria. Circulation 2006; 113:593-595.

7 Cooper LT Jr, Hare JM, Tazelaar HD, Edwards WD, Starling RC, Deng MC, Menon S, Mullen GM, Jaski B, Bailey KR, Cunningham MW, Dec GW; Giant Cell Myocarditis Treatment Trial Investigators: Usefulness of immunosuppression for giant cell myocarditis. Am J Cardiol. 2008;102:1535-1539.
Parrillo JE, Cunnion RE, Epstein SE, Parker MM, Suffredini AF, Brenner M et al: A prospective, randomized, controlled trial of prednisone for dilated cardiomyopayhy. $\mathrm{N}$ Engl J Med 1989;321:1061-1068.

-9 Mason JW, O'Connell JB, Herskowitz A, Rose NR, McManus BM, Billingham ME, et al: A clinical trial of immunosuppressive therapy for myocarditis. The Myocarditis Treatment Trial Investigators. N Engl J Med 1995;333:269-275.

10 Wojnicz R, Nowalany-Kozielska E, Wojciechowska C, et al: Randomized, placebocontrolled study for immunosuppressive treatment of inflammatory cardiomyopathy: two-year follow-up results. Circulation 2001;104:39-45.

11 Frustaci A, Chimenti C, Calabrese F, Pieron M, Thiene G, Maseri A: Immunosuppressive therapy for active lymphocytic myocarditis: virological and immunologic profile of responders versus nonresponders. Circulation 2003;107:857-863.
2 Kühl U, Pauschinger M, Schwimmbeck PL, Seeberg B, Lober C, Noutsias M, et al: Interferon-beta treatment eliminates cardiotropic viruses and improves left ventricular function in patients with myocardial persistence of viral genomes and left ventricular dysfunction. Circulation 2003;107:27932798.

13 Angelow A, Weitmann K, Schmidt M, Schwedler S, Vogt H, Havemann C, et al: The German Transregional Collaborative Research Centre 'inflammatory cardiomyopathy: - molecular pathogenesis and therapy'. Methods and baseline results from a 3centre clinical study. Cardiology 2009;113: 222-230.

-14 Caforio AL, Calabrese F, Angelini A, Tona F, Vinci A, Bottaro S, et al: A prospective study of biopsy-proven myocarditis: prognostic relevance of clinical and aetiopathogenetic features at diagnosis. Eur Heart J 2007;28:

$1326-1333$.
Kindermann I, Kindermann M, Kandolf R, Klingel K, Bultmann B, Muller T, et al: Predictors of outcome in patients with suspected myocarditis. Circulation 2008;118:639648.

16 Mahrholdt H, Goedecke C, Wagner A, Meinhardt G, Athanasiadis A, Vogelsberg H, Fritz P, Klingel K, Kandolf R, Sechtem U: Cardiovascular magnetic resonance assessment of human myocarditis: a comparison to histology and molecular pathology. Circulation 2004;109:1250-1258. 